International Journal of

Health, Medicine and

Nursing Practice

(IJHMNP)

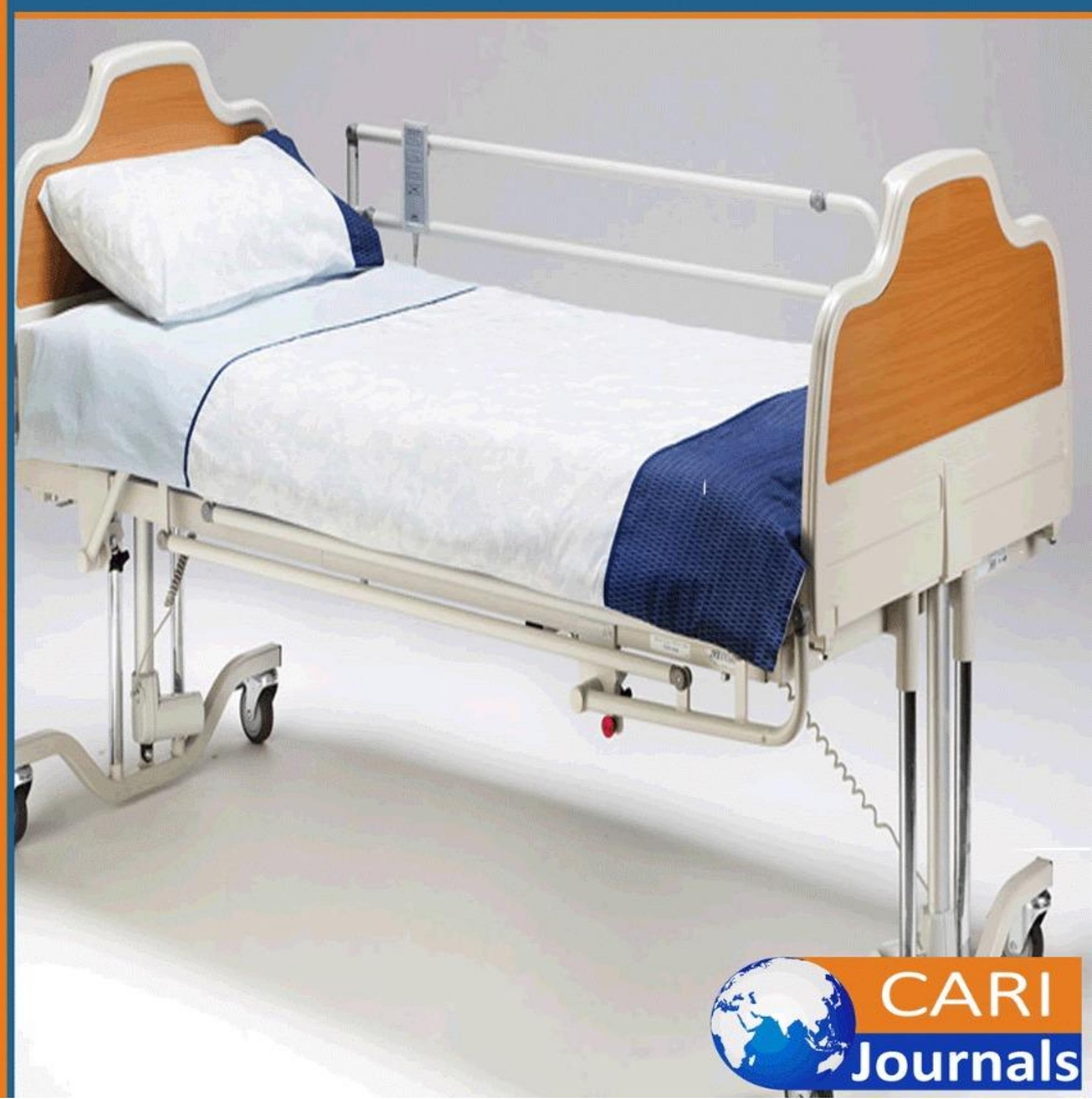




\title{
Awareness, Behavior, and Practices of Nurses related to Nursing Ethics, in tertiary care Hospitals of Lahore, Pakistan
}

\author{
${ }^{1 *}$ Shazia Javed \\ Student Post RN,Bsn: Lahore School of Nursing, The University of Lahore, Pakistan \\ ${ }^{2}$ Kousar Parveen \\ Assistant Professor: Lahore School of Nursing, The University of Lahore, Pakistan \\ ${ }^{3}$ Mohammad Afzal, \\ Associate Professor, Principal: Lahore School of Nursing, The University of Lahore, Pakistan \\ ${ }^{4}$ Prof. Dr Syed Amir Gillani \\ Dean: Faculty of Allied Health Sciences, The University of Lahore, Pakistan \\ Corresponding Authors E-mail: shazshazay@gmail.com
}

\begin{abstract}
Purpose: The objective is to determine nurse's knowledge about Nursing Ethics and association with behavior and practice of these nurses.

Methodology: Cross-sectional Study Design. This study is conducted in different hospital settings of Lahore. a total of 150 nurses are selected by convenient sampling technique. They are taken informed consent and the data was collected including demographics and the nursing ethics. Data was analysed on SPSS version 24.0

Results: Most of the nurses working in different hospital are females and in our participants, $76 \%$ are females while $24 \%$ are males. Mostly belongs to age group of 20-30 years. Nearly $87 \%$ of the participants are single, i.e. hasn't married yet. The more qualified nurse, more the KAP of nursing ethics in hospitals

Unique contribution to theory, policy and practice: The study results show that the nurses need to gain better insight into the legal aspects of their profession and to enhance their level of respect, particularly for nurses of lower age, with a history of employment and contractual strength.
\end{abstract}

Keywords: Knowledge. Behavior, Practice, Nurses, Nursing Ethics

\section{Introduction}

In today's world, "we are under the throes of a massive ethical leap that embraces all humanity essentially" (Donahue, 1996, p. 484). Scientific and technological progress and economic realities, pluralistic world views, and global connectivity make it hard for nurses to disregard the major ethical challenges facing the global community, their daily lives, and their jobs. With divisive and delicate ethical questions challenging healthcare workers and other health practitioners, many professionals have come to appreciate conventional ethical philosophies and different perspectives.Not all are ethical directives obvious, and often people disagree about the correct and the incorrect. Some think that these variables can only be founded on personal views. 
However, to join the global ethics dialog, nurses have more to do than do ethics based on the personal opinions, intuition, or unexamined views of others. To recognize and discuss ethical concerns and problems relating to nursing throughout the 21 st century, nurses need to have a basic understanding of definitions, values, methods as well as theories employed in researching ethics throughout history. Ethical sensibilities, mature and vital for ethical practice, "we must grow our souls, our minds" as Hope (2004) suggested. (Butts \& Rich, 2020)

Nursing is an important profession that affects people, families, and communities' lives, health, and well-being. The nursing career is regulated both by ethics and law principles because these are instruments that provide the nurse with a broad idea of how she would be required to transition from the safe environment of the school to society. (Aliyu, 2015)

There are four principles of ethics

\section{Respect for autonomy}

The idea of autonomy is derived from the Greek terms autos and nomos that mean autonomy or autonomy. Two requirements must be met for a person to be independent: agency (the ability of the individual to act purposefully) and independence (freedom from influences that are controlling). Regulations that are supported by autonomy values include: telling the truth; respecting other people's privacy, protecting sensitive information, gaining consent for patient involvement, and, upon request, helping others decide importantly.

\section{Beneficence and non-maleficence}

These two principles call for practitioners to do well and to prevent or reduce harm. It involves a balance of advantages and harms. The rules governing such values include: you should not cause evil or harm; you should avoid evil or harm; you should take away evil or harm; you should do or encourage good.

\section{Justice}

This theory is directed at people being treated equally, but the principles of justice are more than one. A formal theory of justice is that 'just and unequal treatment' should be handled. In what respect should we ask "fair" and "unequal?" The material principles include: for each person, "according to rules and actions which maximize the use of the society;" for each one, "a maximum of freedom and property" as per 'free market trade;" for each individual "a fair distribution of goods according to moral communities" (Chadwick \& Gallagher, 2016).

Nurses are usually confronted with ethical situations that are not always appropriately handled and are often in an ethical dispute. Ethical conflict is also called moral conflict and is used in nursing literature as a synonymous concept. Moral conflict is defined as "any situation in which regulatory factors such as moral principles and value conflicts demand incompatible acts.Ethic disputes can lead to a variety of forms of psychological distress for the health care provider, including dissatisfaction, impotence, frustration, or indignation. Therefore the level of patient care may be affected. (Kim, Oh, \& Kong, 2020).

\section{Ethical decision-making}

The ETHICS framework (Gallagher 2008) has the following elements: 
Enquire about the facts of the case/situation

Think/talk through the options available to those involved

Hear the views of those involved

Identify relevant principles and virtues

Clarify the meaning of the key principles and values

Select a course of action, present ethical arguments, and review (Chadwick \& Gallagher, 2016).

\section{Problem Statement}

Nursing ethics is in use in every nurse, during every second of hospital life. As the ethical dilemmas are increasing day by day, due to increasing technology involvement and advancements. Above all, there is one major issue is the conflicting values of nursing and the patients and religious values. Therefore, there is a need to observe the use of nursing ethics and other ethical values by the nurses to maintain the safety and the ethical values of the patients.

\section{Purpose of the Study}

The purpose of the study is to check out the knowledge of nurses related to ethics, what is their behavior related to ethics, and above all the use of ethics in their duty hours or during patient dealing and care.

\section{Objectives of Study}

The objectives of the study are

1) Determine the level of knowledge of nursing ethics in the staff nurses.

2) Assess the behavior of the staff related to nursing ethics.

3) Assess the use of nursing ethics by the staff during patient care.

\section{Literature Review}

If we can train good, systematic, holistic caregivers, we can strengthen the nursing profession. The nurse's effect on the health system will then increase, and health care recipients will become more satisfied.Some research on ethics codes of nursing students and nurses has been carried out but the findings are inconsistent. For example, $70 \%$ and $86 \%$ of nursing staff and $53 \%$ of nursing staff characterized adherence to ethical standards as acceptable, according to one trial. Nursing students regularly visit school hospitals and experience ethical problems with patients and nurses. While most nursing professionals were knowledgeable of and important to nursing ethics, they were very concerned because of their ability to enforce ethical codes in clinical environments. (Bijani. 2017)

The moral distress of nurses was induced primarily by care or treatment that was futile or insufficient, as opposed to patient wishes. The most commonly recognized ethical dispute among nurses who wanted to provide guiding principles for the elderly was insufficient treatment due to lack of resources or inadequate healthcare providers. The general and ethical conflict characteristics by geriatric nurses in prior studies have shown little about personal and specific knowledge of ethical clashes and about the nature of ethical clashes faced by nurses in geriatric 
hospitals, which was our primary research issue. Listening to the perceptions of ethical conflicts by their actual voices is vital, to gain information to encourage and facilitate the practical resolution of their ethical conflicts. The key research question was about the general features and tendencies of ethical conflicts in the case of geriatric nurses, and little is known about personal and special perceptions of ethical conflicts in geriatric hospitals as they are encountered in ethics. We must listen to the experiences of ethical conflicts in our actual voices and learn how to encourage and help them in realistic ways to resolve their ethical conflicts. (Kim, Oh, \& Kong, 2020)

After frequent, ineffective ethical conflicts, nurses find it difficult to overcome ethical conflicts themselves, hospitals inept, and hospitals powerless. The infants intended to abandon their work as a last resort, instead of sacrificing their values in nursing, to prevent ethical problems. "When the heat is not standing, get the kitchen out." In their words. Nurses agreed that workers' understanding of ethics would help better handle ethical issues in the context of geriatric treatment. Nursing students also pointed out that nurses should focus on the importance of their ethics in the practice of good treatment for elderly people. For ethical reasons, an approach to treatment has been proposed rather than an approach called principlism, namely reverence for autonomy, charity, maliciousness, and justice, as this will make it possible for nurses to be more attentive and sensitive to the viewpoint of patients. (Juujärvi, Ronkainen, \&Silvennoinen, 2019)

The origins of such phenomena were more centered in most of those studies. Ethical disputes arose from incompatible goals for patients, substitutes, nurses, doctors, and organizations related to treatment and outcomes. For example, caregivers have felt that insufficient healthcare is one of the obstacles or challenges to ethical treatment in long-term hospitals. (Choe, Kang, \& Lee, 2018) The ethical behavior, preparation, knowledge, and regulations of infants have influenced their personal history. Emergency or pandemic cases are not covered by the Ethics Code for the National Association of Nurses in Israel. However, this recognizes the right for nurses to selfcare, whereby nurses are invited to maintain harmony between their work and personal life to protect their health, in times of routines or crisis. (Sperling, 2020)

Ethics used to be seen to be a "personal matter" and relied on individual vulnerabilities, behaviors, engagement, and prior experiences, to help and to gain (e.g., ethical reflection). The managers did not seem to differentiate between their ethical duty and the responsibility of each employee to provide ethical treatment. It is a tension of knowing the "right thing to do but experiencing institutional or another restriction, making it hard to follow the desired path" that arises from contradictions of principles, standards, and interests. The conflicting principles of ethical dilemmas for clinical nurses thus typically lead to a compromise of personal and professional values and a jeopardized capacity of nurses to provide high-quality, sympathetic care. (Haahr, Norlyk, Martinsen, \& Dreyer, 2019)

68 percent of medical staff in China are nursing workers as primary caregivers of COVID-19 persons. New wards have been developed to focus patients to prevent the disease outbreak. Patients with COVID-19 were experiencing challenges such as an unpredictable working climate, disease exposure, lack of skills in their new employment, and near public and media coverage. These elements can place the nurses within ethical challenges that could lead the 
nurses to intense thoughts (like anxiety or terror) and mental stress (such as sleeplessness or restlessness).(Jia et al., 2020)

While ethics and professional principles are global problems, culture may play an important role, and despite the importance of teaching professional ethics and its implications on the performance of the employees, they may be damaging if particular social, economic, and geographical characteristics are not taken carefully into account. Education on professional ethics should also be instructed in light of the social and cultural contexts that are relevant. The first step should be taken to define the current position of people living in the area towards ethics to develop an educational program for ethics in each state. Those students from various medical fields need to develop and explain the principles of professional ethics in different ways, considering both the importance of professional ethics in preserving the dignity of patients, on the one hand and of medical staff, on the other, along with the improvement of working conditions and the increased positive impacts of health services on the other.(Jafari, Khatony, Abdi, \&Jafari, 2019)

\section{Study Gap}

Till today, very few studies are conducted on nursing ethics, to check out the awareness and so on. However, in Pakistan, no such study is conducted in the last five years to check out the KAP of Nursing Ethics among Pakistani Nurses.

\section{Research methodology}

\section{Study Design}

The study design used for this study was cross-sectional descriptive.

\section{Research Setting}

This study was conducted in Tertiary Care Hospitals in Lahore.

\section{Study Population}

The population of the study was the nurses of the tertiary care hospital, who are currently employed.

\section{Sample Size}

The sample size of the study was consist of 150 Staff Nurses who are currently employed.

\section{Sampling Technique}

The sample will be recruited through the convenient sampling method.

\section{Instrument}

The instrument which will be used for this study consists of 21-items. This questionnaire is about Awareness, Behavior, and practice of nursing ethics and law by Nurses in tertiary care hospitals. This questionnaire will be administered to 150 selected samples.

\section{Inclusion Criteria}


Inclusion criteria will be:

i) The staff will be present at the time of data collection.

ii) Those who had completed their Post RN, or BS in Nursing.

\section{Exclusion Criteria}

Exclusion criteria will be:

i) The staff who are working in more than one place at a time.

\section{Data Collection Procedure}

Data was collected from March 2021 to May 2021in the tertiary care hospitals of Lahore.

i) The data collector will introduce the purpose and nature of the current study.

ii) The data collector will obtain informed consent before data collection.

iii) The questionnaire will be distributed during free time.

iv) The tool will be collected after a day so that they can fill up the questionnaire in their free time.

\section{Ethical Considerations}

Ethical approval will be obtained from the university ethical committee and informed consent will be obtained from every participant before data collection. The data collected will be kept confidential and anonymity will be maintained. The data collection files will be password protected and the questionnaire will be placed in a locker.

\section{Data analysis}

Data analysis will be performed over SPSS version 21.0. The descriptive statistics will be checked and Chi-square will be used to check out the association between Awareness, Behavior, and Practices.

\section{Results}

Demographics are given in the table I, most of the nurses working in different hospital are females and in our participants, $76 \%$ are females while $24 \%$ are males. Mostly belongs to age group of 20-30 years. Nearly $87 \%$ of the participants are single, i.e. hasn't married yet. Nearly half of the participants working in different hospitals have RN and SRN qualification, as 54.7\%, while $35.3 \%$ have just RN or the four year BSN generic degree. Just $10 \%$ are those who has done PBSN after RN and SRN.

\begin{tabular}{|c|c|c|c|}
\hline \multicolumn{2}{|c|}{ Demographic Variable } & Frequency & Percentage \\
\hline \multicolumn{4}{|l|}{ Age } \\
\hline a) & 20-30 years & 140 & $93.3 \%$ \\
\hline b) & $31-40$ years & 10 & \\
\hline Gender & & & \\
\hline
\end{tabular}


International Journal of Health, Medicine and Nursing Practice ISSN 2520-0852 (Online)

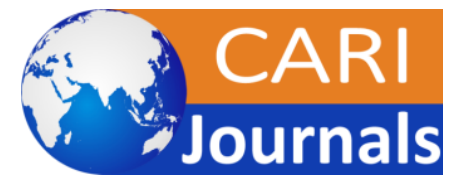

Vol.3, Issue No. 3, pp 1-12, 2021

\begin{tabular}{|c|c|c|c|}
\hline $\begin{array}{l}\text { a) } \\
\text { b) }\end{array}$ & $\begin{array}{l}\text { Male } \\
\text { Female }\end{array}$ & $\begin{array}{c}36 \\
114\end{array}$ & $\begin{array}{l}24.0 \% \\
76.0 \%\end{array}$ \\
\hline
\end{tabular}

\section{Marital Status}

a) Single

b) Married

$130 \quad 86.7 \%$

\begin{tabular}{l|l}
$20 \quad 13.3 \%$
\end{tabular}

\section{Professional Qualification}

a) $\quad \mathrm{RN} / \mathrm{BSN}$

b) $\mathrm{RN}, \mathrm{SRN}$

c) $\mathrm{RN}, \mathrm{SRN}, \mathrm{PBSN}$

\section{Professional Experience}
a) $\leq 5$ years
b) 6-10 years
c) 11-15 years

119

$79.3 \%$

$54.7 \%$

15

$10.0 \%$

$\begin{array}{|cl|} & \\ & \\ \text { Professional Ranks } \\ \text { a) } & \text { Senior Nursing Officer } \\ \text { b) } & \text { Nursing Officer } \\ \text { c) } & \text { Staff Nurse }\end{array}$

30

$20.0 \%$

01

$00.7 \%$

c) Staff Nurse

01

$00.7 \%$

13

$08.7 \%$ 
$136 \quad 90.7 \%$

Table 1

About $80 \%$ of the participants have experience less than 5 years it means they are freshly graduated, or studying on weekend bases or doing both by managing the duty time periods. $90 \%$ of the participants are working as staff nurse.

\begin{tabular}{|l|c|c|c|}
\hline \multicolumn{1}{|c|}{ Statement } & $f$ & Yes (\%) & No(\%) \\
\hline Have you heard of ethical dilemma before? & 150 & $123(82.0)$ & $27(18.0)$ \\
\hline $\begin{array}{l}\text { Ethical dilemmas require an individual to make a choice between } \\
\text { two equal unfavorable alternatives. }\end{array}$ & 150 & $146(97.3)$ & $04(02.7)$ \\
\hline $\begin{array}{l}\text { Code of nursing ethics sets out the ethical behaviors expected of } \\
\text { all registered nurses. }\end{array}$ & 150 & $150(100.0)$ & $00(00)$ \\
\hline $\begin{array}{l}\text { Documentation of nursing activities can be tendered in the law } \\
\text { suits as evidence. }\end{array}$ & 150 & $48(32.0)$ & $102(68.0)$ \\
\hline
\end{tabular}

\section{Table 2}

Knowledge of the participants about nursing ethics is given in table 2. As the most of the participants have some knowledge about ethical dilemma. $82 \%$ has heard about it, while $97 \%$ has marked the right definition, while $100 \%$ has claimed that the code of nursing ethics set out the ethical behavior for nurses. They lack knowledge on one point that the documentation serve as a law suit evidence. Nearly $32 \%$ had claimed that the documentation serve as evidence.

\begin{tabular}{|c|c|c|c|}
\hline Variables & $\mathbf{N}$ & $\chi^{2}$ & $P$-value \\
\hline \multicolumn{4}{|l|}{ Years of experience } \\
\hline Have you heard of ethical dilemma before? & 150 & 3.812 & 0.149 \\
\hline Do you understand the term beneficence? & 150 & 0.297 & 0.862 \\
\hline $\begin{array}{l}\text { Ethical dilemmas require an individual to make a choice } \\
\text { between two equal unfavorable alternatives. }\end{array}$ & 150 & 0.088 & 0.957 \\
\hline Patient's wishes must always be adhered to. & 150 & 1.751 & 0.417 \\
\hline
\end{tabular}


International Journal of Health, Medicine and Nursing Practice

ISSN 2520-0852 (Online)

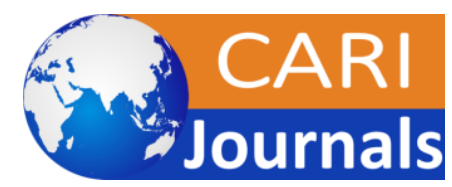

Vol.3, Issue No. 3, pp 1-12, 2021

www.carijournals.org

Nurses has the highest law suits among healthcare provider.

150

0.315

0.854

\section{Professional rank}

Consents should be obtained only for operations, not for nursing

150

1.390

0.499 procedures

Do you approach when faced with ethical and legal problems?

150

0.115

0.944

\section{Professional qualification}

Do you think ethical and legal issued can be reduced?

150

18.231

0.000

Sex

What do you understand by beneficence

150

0.007

0.935

\section{Age group}

Have you heard of ethical dilemma before?

Patient's wishes must always be adhered to.
150

3.513

150
0.048

0.827

$p=0.05$ Significance

Table 3

Table 3 gives the association between the different demographic variables and different factors of knowledge, attitude and practices. As the professional qualification is the major factor playing role in the nursing ethics practices.

\section{Discussion}

The study findings of this study revealed that the most of participants and working staff in the hospitals are females as their percentage is about $76 \%$ while the female to male ratio comes out to about 3:1. Nearly $50 \%$ of them are RN, and Specialized Register Nurse qualified. While remaining $35 \%$ has just RN or BSN qualification. About $10 \%$ are those who has done RN, SRN and after SRN completed Post RN (PBSN). Most of the participants have experience equal to or less than 05 years. Professional qualification is one major factor that is significant in determining the knowledge, attitude and practices of nursing ethics and laws. This states that the more qualified nurse, more the KAP of nursing ethics in hospitals.Lectures and books as leading sources of getting knowledge and learning healthcare ethicsamongst medical students, physicians and nurses.(Adhikari et al., 2016)

Most of the participant ( $82 \%$ ) know about the nursing ethics already as they had learned it in hospital policies, during their course work during study periods and the code of ethics for nurses. These study results are comparable with the study conducted in Bida, Nigeria during 2015. They claimed that their $82 \%$ of the participants have some knowledge related to nursing ethics and law. The $97 \%$ of the participants know the definition of the nursing ethics and ethical dilemma as 
the ethical dilemma can be defined as a choice between two unfavorable conditions. These study results are also comparable to the study findings conducted at Nigeria in 2015. (Aliyu, 2015) Their $95 \%$ of participants know the true definition of ethical dilemma. While $100 \%$ of them claimed that the code of ethics define the ethical behavior expected, by the world, of nurses.

Professional qualification has only relationship with the ways to reduce the ethical dilemmas in future. There is association between professional qualification and reduction in ethical dilemmas. Nearly half of the participants think that the consent should be obtained for nursing procedures too, not just for the operations or other major procedures. These results are comparable to a study conducted in Nepal. They claimed the same results that the consent should be obtained for every procedure whether it is nursing procedure or any other major procedure, it could be verbal or the written consent.(Akyüz et al., 2018)

A study conducted in Sub Sharan Africa, according to this study results, $44 \%$ of their respondents claimed that the patient wishes should always be adhered but in our study, similar results were concluded. Nearly $46 \%$ of our respondents had said that patient whishes must be adhered always. As it is following the principle of Autonomy. Another consequence of compliance with human autonomy is medical confidentiality. Health care staff pledge their patients directly or implicitly to keep the details they are given as a matter of professional code of conduct private. Promises are also a way of preserving the sovereignty of citizens. It also is doubtful that the extremely privately held and sensitive information required for their optimum treatment would be divulged without such assurances of confidentiality. (Monsudi et al., 2017)

A study conducted in Turkey, in 2018, 32.6\% of participants said that consent should be obtained from patients before any procedure, whether it is nursing procedure or any other operative procedure. While this study results are comparable to us, but in our study more than half of participants $(52.7 \%$ ) claimed this point. (Akyüz et al., 2018)

\section{Limitations and Conclusion}

\section{Limitations}

Limitations of this study are:

a) This is conducted on a small scale so its findings can't be generalized on large scale.

b) This study has a small sample size.

\section{Recommendations}

A similar study should be conducted on large scale with a large sample size, so its findings should be generalized on large scale.

\section{Conclusion}

The study results show that the nurses need to gain better insight into the legal aspects of their profession and to enhance their level of respect, particularly for nurses of lower age, with a history of employment and contractual strength. It is believed to lead to the solution to these problems through an increasing level of education along with the establishment of official policies and procedures. 
International Journal of Health, Medicine and Nursing Practice

ISSN 2520-0852 (Online)

Vol.3, Issue No. 3, pp 1-12, 2021

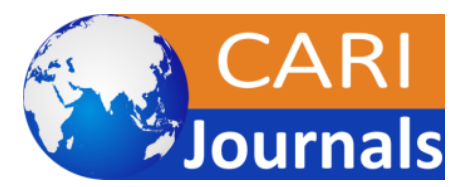

www.carijournals.org

\section{References}

Adhikari, S., Paudel, K., Aro, A. R., Adhikari, T. B., Adhikari, B., \& Mishra, S. R. (2016).

Knowledge, attitude and practice of healthcare ethics among resident doctors and ward nurses from a resource poor setting, Nepal. BMC Medical Ethics, 17(1).

https://doi.org/10.1186/s12910-016-0154-9

Akyüz, E., Bulut, H., \&Karadağ, M. (2018). Surgical nurses' knowledge and practices about informed consent. Nursing Ethics, 26(7-8), 2172-2184.

https://doi.org/10.1177/0969733018810767

Aliyu, D. (2015). Knowledge, attitude and practice of nursing ethics and law among nurses at federal medical centre, bida. American Journal of Health Research,3(1), 32-37.

doi:10.11648/j.ajhr.s.2015030101.15

Bijani, M., Ghodsbin, F., JavanmardiFard, S., Shirazi, F., Sharif, F., \&Tehranineshat, B. (2017). An evaluation of adherence to ethical codes among nurses and nursing students. Journal of medical ethics and history of medicine, 10, 6 .

Butts, J. B., \& Rich, K. L. (2020). Nursing Ethics: Across the curriculum and into practice. Burlington,, MA: Jones and Bartlett Learning.

Chadwick, R. F., \& Gallagher, A. (2016). Ethics and nursing practice. London: Palgrave.

Choe, K., Kang, H., \& Lee, A. (2018). Barriers to ethical nursing practice for older adults in long-term care facilities. Journal of Clinical Nursing,27(5-6), 1063-1072.

doi:10.1111/jocn.14128

Haahr, A., Norlyk, A., Martinsen, B., \& Dreyer, P. (2019). Nurses experiences of ethical dilemmas: A review. Nursing Ethics,27(1), 258-272. doi:10.1177/0969733019832941

Jafari, H., Khatony, A., Abdi, A., \&Jafari, F. (2019). Nursing and MIDWIFERY students' attitudes TOWARDS principles of medical ethics in KERMANSHAH, Iran. BMC Medical Ethics,20(1). doi:10.1186/s12910-019-0364-Z

Jia, Y., Chen, O., Xiao, Z., Xiao, J., Bian, J., \&Jia, H. (2020). Nurses’ ethical Challenges caring for people with covid-19: A qualitative study. Nursing Ethics, 28(1), 33-45.

doi:10.1177/0969733020944453

Juujärvi, S., Ronkainen, K., \&Silvennoinen, P. (2019). The ethics of care and justice in primary nursing of older patients. Clinical Ethics, 14(4), 187-194.

doi:10.1177/1477750919876250

Kim, M., Oh, Y., \& Kong, B. (2020). Ethical conflicts experienced by nurses in

GERIATRIC hospitals in South Korea: 'IF You CAN'T stand the heat, get out of THE KITCHEN". International Journal of Environmental Research and Public Health, 17(12), 4442. doi:10.3390/ijerph17124442

Monsudi, K. F., Oladele, T. O., Nasir, A. A., \&Ayanniyi, A. A. (2017). Medical ethics in sub-Sahara Africa: closing the gaps. African Health Sciences, 15(2), 673.

https://doi.org/10.4314/ahs.v15i2.47 
International Journal of Health, Medicine and Nursing Practice

ISSN 2520-0852 (Online)

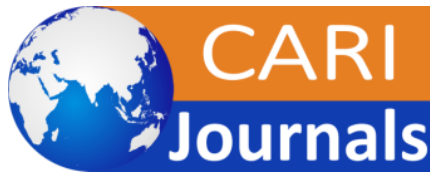

Vol.3, Issue No. 3, pp 1-12, 2021

www.carijournals.org

Sperling, D. (2020). Ethical dilemmas, perceived risk, and motivation among nurses during the COVID-19 pandemic. Nursing Ethics,28(1), 9-22. doi:10.1177/0969733020956376 